\title{
APPLICATION OF GROUND-BASED GPS WATER VAPOR DATA IN THE ANAL YSIS OF TROPICAL CYCLONE SON-TINH HITTING HAINAN ISLAND
}

\author{
Shitai Wang ${ }^{1 *}$,Yuxuan Lin ${ }^{1}$,Wenjun Wang ${ }^{2}$,Boyu Zhang ${ }^{1}$,Dinghong Zhang ${ }^{1}$ \\ ${ }^{1}$ College of surveying and mapping geographic information, Guilin university of technology, Guilin, Guangxi \\ ${ }^{2}$ Huicheng District Branch of Huizhou Land and Resources Bureau, Land and Resources Survey and Mapping Team.
}

KEY WORDS: Tropical cyclone “Son-Tinh”, Hainan Island, Windstorm, GPS, PWV, Meteorological parameters

\begin{abstract}
:
Tropical cyclone as a disaster. In addition to bringing abundant precipitation to the island, the huge wind will affect the public facilities in the island. In serious cases, it directly endangers people's lives and property. Every year, the disastrous damage caused by tropical cyclone causes direct or indirect economic losses to Hainan Island. This paper studies this problem. Based on the tropical cyclone data provided by China Typhoon Network and the information provided by GPS satellite observation data and 16 meteorological observatories in Hainan Island, this paper takes the monitoring of tropical cyclone Son-Tinh No. 9 in 2018 as an example to analyze the changes of meteorological elements and precipitation during the influence period of tropical cyclone. The results show that: The changes of atmospheric pressure, temperature and relative humidity at the stations are very obvious for the transit of tropical cyclones. When the island is affected by tropical cyclones, these parameters will change significantly. Among them, the abnormal changes of atmospheric pressure and temperature can effectively express the time and extent of the influence of tropical cyclone. It can be used as one of the important indicators to judge tropical cyclone before and after landfall. Based on these obvious changes, the influence of the parameters of tropical cyclone Son-Tinh before and after landing on Hainan Island is analyzed. It can effectively analyze the disasters caused by tropical cyclones and provide some reference information.
\end{abstract}

\section{INTRODUCTION}

Tropical cyclones occur on the tropical ocean and often accompanied by a large amount of rain and huge wind. is a natural disasters.In the process of generation and disappearance of tropical cyclones.Many researchers have analyzed and studied the phenomenon and come to some conclusions ${ }^{[4-7,11-12]}$. Since the establishment of GPS meteorology in literature ${ }^{[1]}$.The method of monitoring PWV by ground-based GPS make use of high spatial and temporal resolution has been applied more and more widely.giving provides basic information for meteorological research and weather forecast.Hainan Island is located in the tropics.Perennial disturbance by tropical cyclones.Atmospheric Precipitable Water Volume (PWV) is an important component of the atmospheric system.the precipitation in short term based on wavelet decomposition (WD), genetic algorithm (GA) and least squares support vector machine (LSSVM).Forecast success ${ }^{[10]}$.The main factors affecting tropical cyclones precipitation are analyzed.The conclusion shows that the intensity and topographic effect of tropical cyclone will have a greater impact on precipitation ${ }^{[9]}$.During the influence of tropical cyclones, There is a good corresponding relationship between GPS/PWV and precipitation ${ }^{[3,13]}$.

\section{FSURVEY OF RESEARCH AREAS}

Hainan Island $\left(108^{\circ} 37^{\prime}-111^{\circ} 03^{\prime} \mathrm{E}, 18^{\circ} 10^{\prime}-20^{\circ}\right.$ $10^{\prime} \mathrm{N}$ ) is located in the southernmost provinces of China, which belongs to China.The second large island, Hainan Island, covers an area of about 354,000 square kilometers. It has 16 observation meteorological stations. Meteorological stations are distributed in the northeast, northwest, southwest and southeast of the island in four directions. The rest of the stations are scattered around the island or in the middle of the island. They are distributed in mountain plains. Because they are surrounded by the sea, and they are located in the tropics. The region is affected by southeast airflow all the year round. The abundant precipitation brought by cyclones in the outer heating zone makes the precipitation resources in the island extremely abundant. About 2-4 tropical cyclones affect Hainan Island every year. The season of tropical cyclones in Hainan Island usually occurs in summer and autumn from June to November every year. Most tropical cyclones are mainly from August to October. In addition to bringing abundant precipitation to the island, the huge wind will affect the public facilities in the island. In serious cases, it directly endangers people's lives and property.tropical cyclone Son-Tinh was registered on the coast of Wancheng Town, Wanning City, Hainan Island around 4:50 on July 18, 2018. The maximum

\footnotetext{
* Corresponding author:Shitai Wang - E-mail: 85282788@qq.com

Fund projects: Basic Competence Promotion Project for Young and Middle-aged Teachers in GuangXi Universities: KY2016YB823 GuangXi Natural Science Foundation: 2018GXNSFAA281279
} 
wind force near the centre at landing was $9(23 \mathrm{~m} / \mathrm{s})$.In this paper, Variation characteristics of meteorological parameters produced by tropical cyclone Son-Tinh before and after landing on Hainan Island(hereinafter referred to as “Son-Tinh”).

\section{DATA EXPERIMENTS AND ANALYSIS}

\subsection{Data Sources}

ZGHK, a Radiosonde station in Haikou City, Hainan Island, was selected as an experiment(Source of data:Wyoming State University's official website,http://www.weather.uwyo.edu). Local GPS Ground-based station in Haikou City(Source of data:http://www.cgps.ac.cn).China meteorological data sharing service system(Source of data:http://data.cma.cn).Using the data provided by these websites to analyze "Son-Tinh".

\subsection{Introduction of the Formulas Used in this Paper}

GPS Precipitable Water vapor Originated from GPS Tropospheric Delay Error.which can be obtained by inverse operation of GPS positioning.Chen Mingdong ${ }^{[6]}$ carries on the extraction test analysis through GPS/PWV data and corresponding time of Radiosonde station.The results show that is little difference in accuracy between GPS/PWV and PWV of adiosonde station.Figure 1,The main extraction formulas of GPS/PWV are as follows:

$$
\begin{gathered}
Z W D=Z T D-Z H D \\
P W V=K * Z W D \\
K=10^{6} / \rho R_{v}\left(k_{3} / T_{m}+k_{2}\right)
\end{gathered}
$$

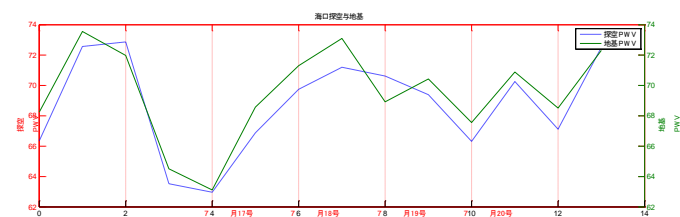

Figure 1. PWV Linear Inversion Map of Haikou Ground-based station and adiosonde station

ZTD is the total tropospheric delay in zenith direction.ZWD is a wet delay in zenith direction.ZHD is a dry delay in zenith direction. $\mathrm{K}$ is the water vapor conversion coefficient, which is related to climate and region. $\rho$ is Water density.Rv is the specific gas constant of water vapor.while Change with time and location.Tm is atmospheric weighted mean temperature $(\mathrm{K}) . k_{2}$ and $k_{3}$ are atmospheric refraction constants. $k_{2}=22.1 \pm$
$2.2 \mathrm{~K} / \mathrm{hpa}, \quad k_{3}=(3.739 \pm 0.012) * 10 \wedge 5 \mathrm{~K}^{2} / \mathrm{hpa}$.Normally,the value of $\mathrm{K}$ varies from region to region and from season to season.Figure 3 of the precipitation distribution on July 17, 2018. “Son-Tinh” close to Hainan Island,Wanning City, the closest to the windstorm, is already in the heavy rainfall zone.Through Kriging Interpolation,Precipitation in Wanning City is about $100 \mathrm{~mm}$.Monitoring station and inversion are little difference in accuracy.Figures 2 and Table 1 show.

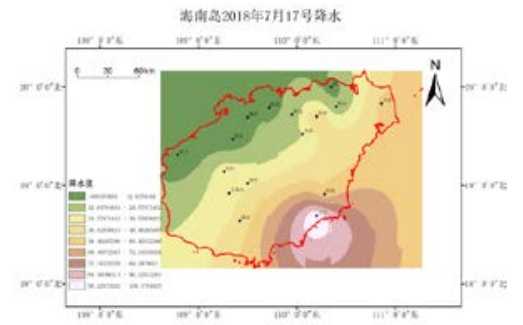

Figure 2. Rainfall Interpolation Distribution Map of Hainan Island on July 17, 2018

\begin{tabular}{|c|c|c|c|}
\hline place & \multicolumn{3}{|c|}{ Precipitation/mm ( 7.17-7.19) } \\
\hline Wanning & 108.6 & 20.7 & 0.9 \\
\hline
\end{tabular}

Table 1 Three-day precipitation in Wanning

"Son-Tinh" moved North by West all the way after landing in Hainan.The precipitation center shifts gradually and the intensity decreases.Figure 3 to 5 are shown. When the windstorm center landed in Wanning City, the platykurtic value of barometric pressure appeared "V" type.As shown in Figure 6.There are some deviations between the peak of the maximum wind speed and the minimum pressure caused by the storm center.Because the eye of a tropical cyclone is windless or very small.When "Son-Tinh" center moves, the peak value of the maximum wind force near the center appears. There is little difference in the accuracy between the inverted images and those published by China Typhoon Network.Meteorological parameters of 16 stations on the island provided by China Meteorological Network.Map of atmospheric pressure distribution over the island from July 17, 2018 to July 19, 2018 by Analysis of Kriging Interpolation Algorithms.Figure 7 to 9 are shown.The air pressure in the central region is lower than that around the island.This phenomenon reflects the factors affected by the topography in the storm center,and also reflects the characteristics of high altitude in the middle of hainan island.

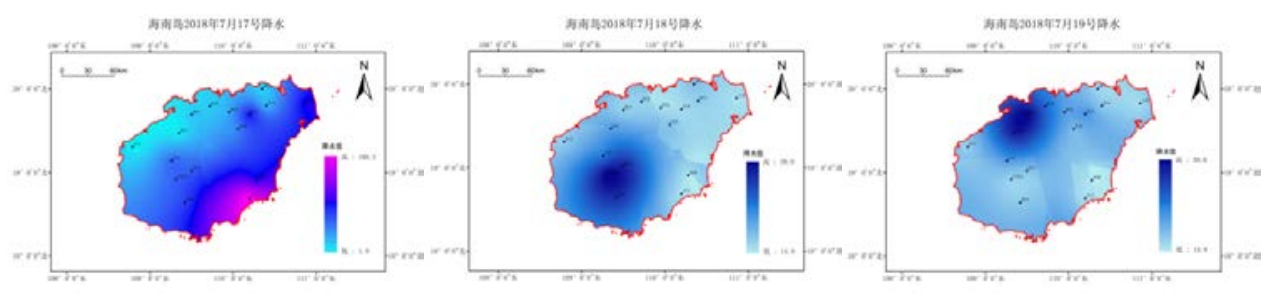

Figure 3 to 5.7.17-7.19 Precipitation Distribution Map for the Island 


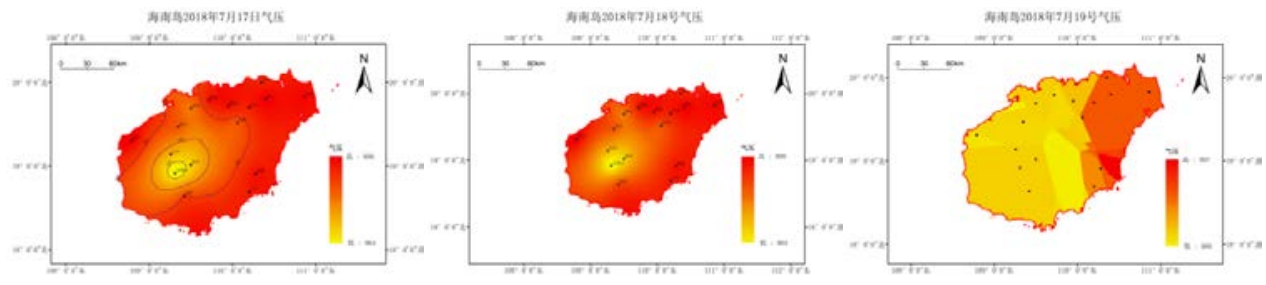

Figure 7 to 9.7.17-7.19 Precipitation Distribution Map for the Island

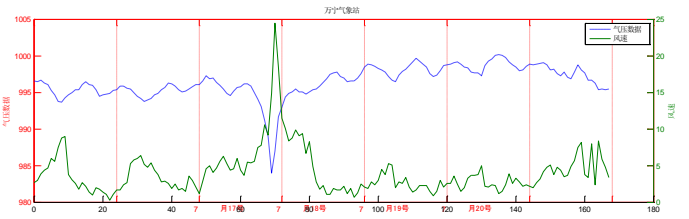

Figure 6. Linear diagram of the relationship between wind speed and air pressure at Wanning Meteorological Station

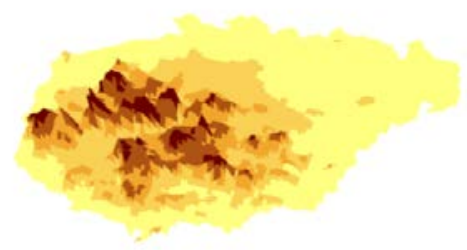

Figure 10. Three-dimensional topographic map of Hainan Island

\subsection{Characteristic changes in air pressure and relative humidity}

According to the meteorological data of relative humidity monitored by wanning station through linear inversion, the peak

data value of relative humidity during the influence period of "Son-Tinh" was longer than the usual duration.

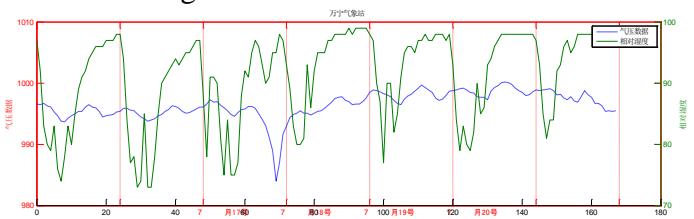

Figure 11. Linear Diagram of the Relationship between Air Pressure and Relative humidity at Wanning Meteorological Station

\subsection{Characteristic changes in air pressure and temperature}

From the inversion linear map of the station, it can be concluded that the platykurtic value of air temperature and the platykurtic value of air pressure are basically consistent during the influence period of "Son-Tinh ", which is a good reflection of the higher sensitivity of tropical cyclone to air pressure and air temperature.

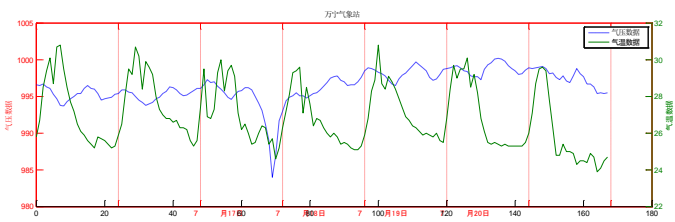

Figure 12. Linear Diagram of the Relationship between Air Pressure and Temperature at Wanning Meteorological Station

\subsection{PWV Characteristic Change}

From the experimental analysis of the Ground-base station in Haikou, it was concluded that the PWV changed during the influence of "Son-Tinh", and there was a time interval between the platykurtic value pressure and the platykurtic value of PWV calculated by the ground-base station.It reflects the time of tropical cyclone to some extent, but has no indication to the strength of tropical cyclone.There is a certain distance between Haikou city and Wanning city,Li Xingguang's literature ${ }^{[10]}$.Since the distribution of water vapor in tropical cyclones is mainly concentrated in the spiral cloud belt where the storm gathers, The spiral cloud belt shows irregular distribution according to the marine environment, and the water vapor information it carries is also unevenly distributed,Therefore,for that the variation of PWV in tropical cyclones can only reflect the time factor of the wind disaster caused by the storm to a certain extent, and can only provide a reference.

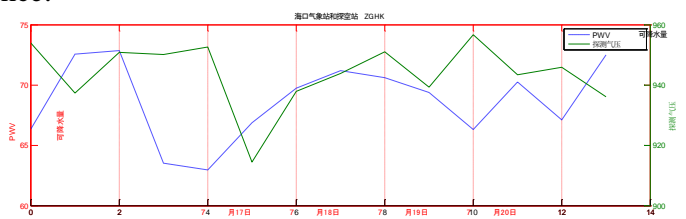

Figure 13. Linear diagram of the relationship between PWV and air pressure in Haikou Ground-base station

\section{CONCLUDING REMARKS}

In this paper, the meteorological parameters of each station are analyzed by experimental inversion, The results show that the change of air pressure, temperature and relative humidity is very obvious to the transit of tropical cyclone.These parameters change significantly when the island is affected by a tropical cyclone.Among of them, the abnormal change of pressure and temperature can effectively express the time and degree of the impact of tropical cyclone.Similarly, the change curve of PWV is related to the duration of tropical cyclone,Through the precipitation value monitored by the station, the time distribution map of precipitation in the island can be retrieved,to some extent, the spatio-temporal variation characteristics of water vapor produced by tropical cyclones in 
this region can be understood, which provides certain reference factors for research on tropical cyclones in the future.

\section{ACKNOWLEDGEMENTS}

Basic Competence Promotion Project for Young and Middleaged Teachers in GuangXi Universities: KY2016YB823

GuangXi Natural Science Foundation: 2018GXNSFAA281279

\section{REFERENCES}

Askne J et al. Estimation of tropospheric delay for microwaves from surface weather data[J]. Radio Sci. 1987.

Chen Mingdong. Study on the variation characteristics of GPS/PWV during the typhoon "Maria" landing in Fujian [J]. Bulletin of Surveying and Mapping / Bull Surv Map. 2018.

Ding Jincai, Huangyan, Ye Qixin, Zhu Wenyao, Song Shuli, Liang Xudong. GPS Observation and Analysis of Precipitable Water Vapor during Typhoon Ramasun in 2002 Influencing East China Coast [J]. Chinese Journal of Atmospheric Sciences. 2004.

Dong Keqin, Li Zengzhong. A Preliminary Study on the Effect of Hainan Island Topography on Typhoon Crossing the Island [J]. Chinese Journal of Atmospheric Sciences. 1980.

Huang Zhen, li Wanbiao, Liang Jun. Application of precipitable water vapor from ground based GPS data to analysis of precipitation weather process [J]. Journal of Meteorology and Environment / J Meteorol Environ. 2013.

Ji chunxiao, Xue Genyuan, Zhao Fang, Yu Zhen, Shou Zhanghan. The Numerical Simulation of Orographic Effect on the Rain and Structure of Typhoon Rananim During Landfall [J]. Chinese Journal of Atmospheric Sciences. 2007.

Kaplan J, De Maria M. On the decay of tropical cyclone winds after landfall in the New England area [J]. Journal of Applied Meteorology. 2001.

Ling Xingguang. Retrieval of Precipitable Water Vapor Using Ground-based GPS within Extreme Weather [D]. China University of Mining and Technology. 2015.

Niu Xuexin, Du Huiliang, Teng Daigao, Liu Jianyong. Main Factors Affecting the Rainfall Caused by Landing Typhoons [J]. Torrential Rain and Disasters. 2010.

Xie Shaofeng, Su Yongliang, Liu Chunli, Liu Lilong. ShortImpending Prediction of GPS Precipitable Water Vapor Based on Wavelet Decomposition and GA-LSSVM [J]. Journal of Geodesy and Geodynamics / J Geod Geodyn. 2019.

Yuan Jinnan, Gu Dejun, Liang Jianyin. A Study of the Influence of Topography and Boundary Layer Friction on Landfalling Tropical Cyclone Track and Intensity [J]. Chinese Journal of Atmospheric Sciences. 2007.

Yan Jinghua, Xu Jianping, Ding Weiyu, Chen Zitong, Liao Yishan. A Modeling Study of the Impact of Terrain on the Intensity of Landfalling Tropical Cyclone Vongfong (0214) [J]. Chinese Journal of Atmospheric Sciences. 2005.
Zou Haibo, shan Jiusheng, Wu Shanshan, Liu Ximing. Improvement of GPS Moisture Solving Method and the Application to Typhoon Induced Heavy $\mathrm{R}$ ainfall [J]. Acta Scientiarum Naturalium Universitatis Sunyatseni. 2013. 